\title{
ANALYTICAL AND NUMERICAL INVESTIGATIONS OF A LATERALLY LOADED SINGLE PILE EMBEDDED IN A COHESIVE SOIL
}

\author{
MaLiK HABEeb AL-LAMI \\ Dept. of Civil Engineering. University of Mustansiriyah-Iraq
}

\begin{abstract}
ABSTRUCT
Finite element analyses have become routine for geotechnical engineers, allowing them for more realistic representation of the actual scenarios. In this article, a 3D nonlinear numerical analyses were conducted to examine the response of a free head single concrete rigid pile, driven in a hypothetical clayey soil and exposed to a lateral load under undrained conditions. Three cases were considered for the soil. In the first case, the soil was taken as one layer of clay whose undrained shear strength is constant with depth. In the second case, however, the soil consisted of two layers of clay. The undrain cohesion of the upper soil, whose thickness is smaller than that of the lower layer. In the third case, the conditions were taken exactly, yet, opposite to the second case. The results of the numerical analysis were compared with the acquired analytical results from Broms' theory. Further, soil resistance along the shaft of examined pile has been obtained from the numerical analysis and compared with the distributions suggested by other studies.
\end{abstract}

KEYWORDS: Finite element analyses; Lateral load; pile; CAM Clay; Broms' Theory.

\section{INTRODUCTION}

$\mathbf{P}$ iles can be exposed to axial and/or horizontal loads depending on the purpose of their application such as power poles, sign posts, marine pilings and earth retaining structures. Their resistance to lateral loads comes from a combination of three core components: bending, shear and soil passive pressure. These components, in turn, relies on:

- Stiffness and strength of the pile

- Strength and stiffness of the soil

- Head conditions, i.e. fixed or free head

Theoretical and numerical techniques have been employed to design and analyse piles exposed to horizontal loads: Barber (1953), Broms (1964), Druery and Ferguson (1969), Banerjee and Davies (1978), Bhushan et al. (1979), Poulos and Davis (1980), Meyerhof et al. (1981,
1985), Prasad (1997), McDonald (1999), Phanikanth et al. (2012), Hazzar et al. (2013) and Mukherjee and Dey (2016). Theoretical approaches are classified into two categories elastic and ultimate load methods. The elastic methods assume both the pile and the surrounding soil to act elastically and can be employed to assess the response of the pile under working loads only. Ultimate limit methods (e.g. Broms, 1965), however, are used to calculate the ultimate lateral capacity of short, rigid, and long, flexible, piles embedded in cohesive or cohesionless soils and subjected to horizontal loads only. While short piles are assumed to act as one unit and fail due to shearing the soil along the shaft as the ultimate lateral load is being approached, Broms assumes that flexible piles fail in bending and form a plastic hinge once the maximum bending moment is reached. Both cases are presented in the Fig. 1. 

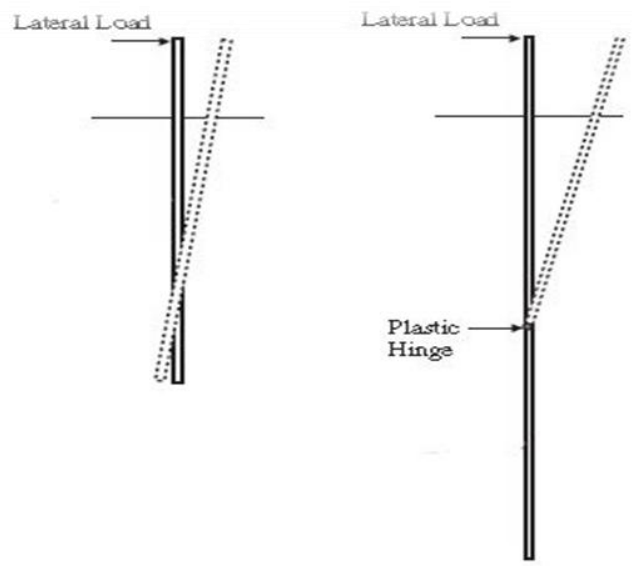

Fig. (1): Failure Mechanism of (a) short and (b) long piles

Broms (1964a and b) developed a theory to work out the ultimate lateral resistance of floating short and flexible piles embedded in purely cohesive or frictional soils and subjected to horizontal loads only. The theory takes into account pile head conditions whether it is fixed or free-head. Broms assumes that soil pressure is zero from the NGL to a depth of $1.5 \mathrm{~d}$ below the ground surface and a value of $9 \mathrm{c}_{\mathrm{u}} \mathrm{d}$ after this depth. This is shown in Fig. 2 (a). Achieving such a resistance requires the pile to move sufficiently and this is an embedded assumption in the theory. Poulos and Davis (1981), however, suggest a different approach to pressure distribution along the shaft of rigid piles embedded in cohesive soils in which, the ultimate lateral resistance rises linearly from 2cud at the NGL to a depth of $3 \mathrm{~d}$ and remains constant after this depth at a value ranging from 8 to $12 \mathrm{cud}$. This is shown in the Fig.

(b).
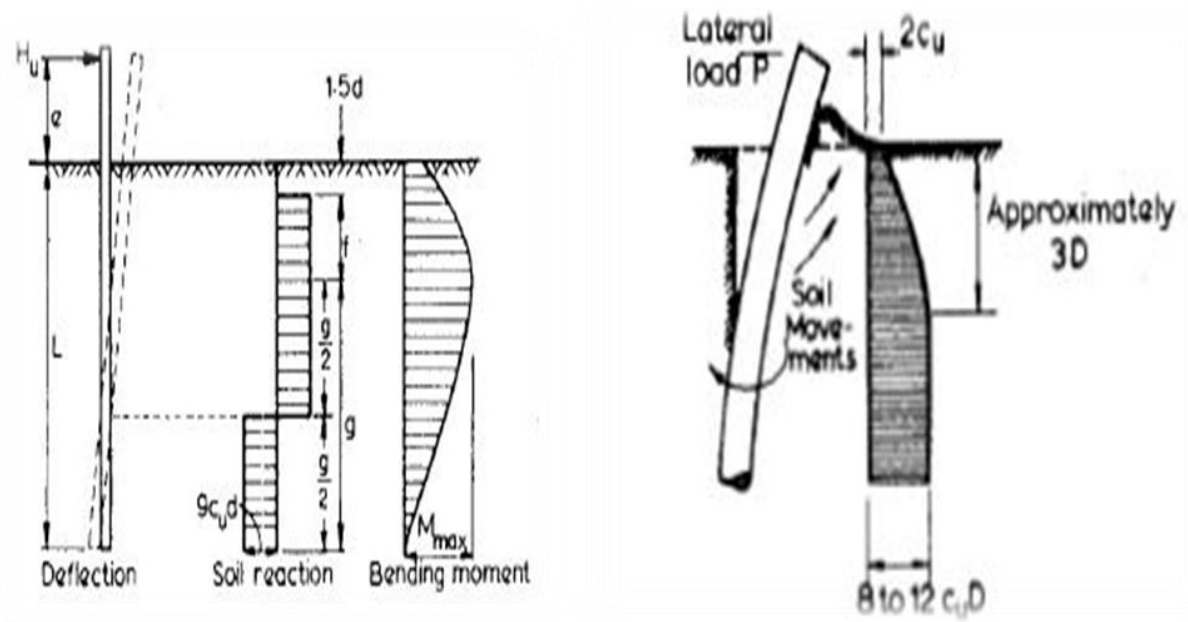

Fig. (2): Distribution of pressure along the shaft of rigid piles (left) Broms (1964), (right) Poulos and Davis (1980)

Broms' approach devices the solutions for short piles in a form of curves that correlate the implanted length of the pile to the pile diameter (L/D), to the normalised ultimate lateral resistance taking into account a range of e/D ratios. This is shown in Fig. 3. If $\mathrm{L} / \mathrm{D}$ is greater than 20, then the pile is regarded as a long pile. 


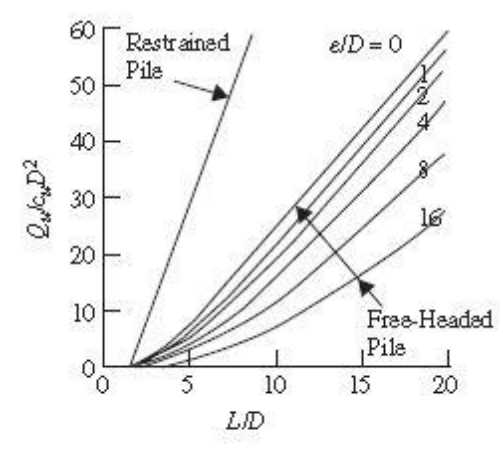

$(\infty)$

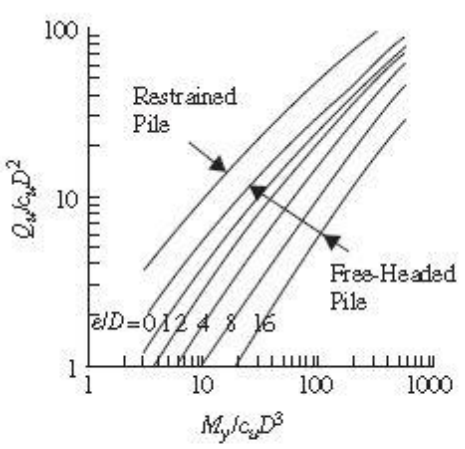

(b)

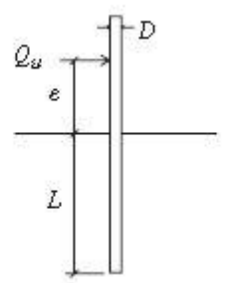

Fig. (3): Broms' method for piles in clayey soils: (a) rigid piles; (b) flexible piles. (Helwany, 2007)

Two and three-dimensional finite element analyses have become routine for geotechnical engineers, allowing them for more realistic representation of the actual scenarios. In this paper, a three-dimensional nonlinear numerical analysis was conducted to examine the behaviour of a single concrete rigid pile, driven in a hypothetical clayey soil and subjected to a lateral load under undrained conditions. The diameter of the pile is $0.8 \mathrm{~m}$, and its embedded length is $4 \mathrm{~m}$. Instead of applying a horizontal load at a distance from the ground surface, a moment was applied to the pile head at the NGL. Three cases were considered for the soil. In the first case, the soil was taken to be one layer of clay whose undrained shear strength is constant with depth and equals to $160 \mathrm{kPa}$. In the second case, however, the soil consisted of two layers of clay. The undrain shear strength of the upper soil, whose thickness is $2 \mathrm{~m}$, is lower than that of the lower layer, whose length is $8 \mathrm{~m}$. In the third case, the conditions were taken exactly, yet, opposite to the second case with regard to the undrained shear strength. The outcomes of the numerical analysis were likened with the acquired analytical results from Broms' theory. Further, soil resistance along the shaft of examined pile in the first case has been obtained from the numerical analysis and compared with the distributions suggested by Broms (1964) and Poulos and Davis (1980). All the cases and the soil properties are summarised in Table 1.

\section{NUMERICAL MODEL}

A three-dimensional nonlinear numerical analyses were conducted to study the response of a free head single concrete rigid pile, driven in a hypothetical clayey soil and subjected to a lateral load under undrained conditions. The FE code, ABAQUS 6.12, was chosen for this purpose owing to its outstanding ability in simulating different scenarios, consisting of different material stiffness and interactions. Unlike axially loaded piles, laterally loaded piles are three-dimensional by nature and were dealt with as such herein. However, since the proposed scenario is symmetric about the action line of the applied horizontal load, only half of the pile and the soil mass were modelled. The soil mass is $30 \mathrm{~m}$ long in the $\mathrm{x}$-direction, $8 \mathrm{~m}$ wide in the y-direction and $10 \mathrm{~m}$ high in the z-direction. Those dimensions were chosen such that they had minor, if no, effects on the analyses. A single concrete rigid pile was driven at the centre of the soil mass. The pile has a circular cross section with a diameter of $0.8 \mathrm{~m}$, and its embedded length is $4 \mathrm{~m}$. An overturning moment was applied at the NGL. The meshed numerical model is shown in Fig. 4. The surplus pore water pressure resulting from driving the pile was assumed to be completely dissipated before the application of the moment. 
Journal of University of Duhok, Vol. 20, No.1 (Pure and Eng. Sciences), Pp 251-258, 2017

elSSN: 2521-4861 \& pISSN: 1812-7568

https://doi.org/10.26682/sjuod.2017.20.1.23

Table (1): Soil Properties

\begin{tabular}{|c|c|c|c|c|c|c|}
\hline \multicolumn{7}{|c|}{ Case 1. (One layer) } \\
\hline $\mathrm{T}(\mathrm{m})$ & $\mathrm{Cu}(\mathrm{KPa})$ & $E(\mathrm{MPa})$ & $v$ & $\lambda$ & G (MPa) & $k(m /$ day $)$ \\
\hline 10 & 160 & 55 & 0.35 & 0.165 & 8 & $25^{*} 10^{-6}$ \\
\hline \multicolumn{7}{|c|}{ Case 2 (Two layers) } \\
\hline \multicolumn{7}{|c|}{ Layer one } \\
\hline $\mathrm{T}(\mathrm{m})$ & $\mathrm{Cu}(\mathrm{KPa})$ & $\mathrm{E}(\mathrm{MPa})$ & $v$ & $\lambda$ & G (MPa) & $k(m /$ day $)$ \\
\hline 2 & 160 & 55 & 0.35 & 0.165 & 8 & $25 * 10^{-6}$ \\
\hline \multicolumn{7}{|c|}{ Layer 2} \\
\hline $\mathbf{T}(\mathrm{m})$ & $\mathrm{Cu}(\mathrm{KPa})$ & $\mathrm{E}(\mathrm{MPa})$ & $v$ & $\lambda$ & $\mathrm{G}(\mathrm{MPa})$ & $k$ (m/day) \\
\hline 8 & 200 & 68 & 0.35 & 0.18 & 14 & $25^{*} 10^{-6}$ \\
\hline \multicolumn{7}{|c|}{ Case 3. (Two layers) } \\
\hline \multicolumn{7}{|c|}{ Layer 1} \\
\hline $\mathrm{T}(\mathrm{m})$ & $\mathrm{Cu}(\mathrm{KPa})$ & $E(M P a)$ & $v$ & $\lambda$ & G (MPa) & $k(m /$ day $)$ \\
\hline 2 & 200 & 68 & 0.35 & 0.18 & 14 & $25^{*} 10^{-6}$ \\
\hline \multicolumn{7}{|c|}{ layer 2.} \\
\hline $\mathbf{T}(\mathrm{m})$ & $\mathrm{Cu}(\mathrm{KPa})$ & $\mathrm{E}(\mathrm{MPa})$ & $v$ & $\lambda$ & $\mathrm{G}(\mathrm{MPa})$ & $k$ (m/day) \\
\hline 8 & 160 & 55 & 0.35 & 0.165 & 8 & $25^{*} 10^{-6}$ \\
\hline
\end{tabular}

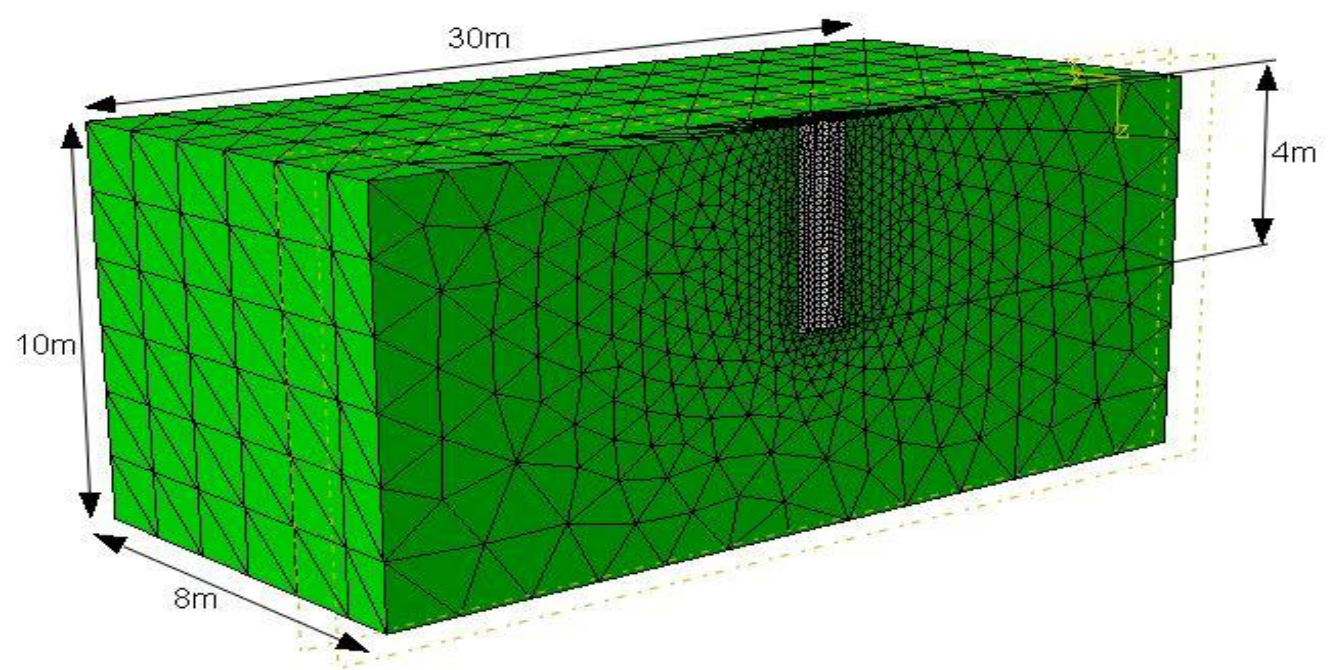

Fig. (4): The meshed model

3. CONSTITUTIVE MODEL 
The response of the pile was made to be elastic throughout the analysis, and identified by the Young's modulus and Poisson's ratio. The stressstrain behaviour of the soil was simulated by the Modified CAM Clay Model, implemented in the FE Code. The Modified CAM Clay model is an elastic-plastic model, based on Critical State theory and adopts that there is a logarithmic relationship between the mean effective stress ( $\left.p^{\prime}\right)$ and the void ratio (e) (?). This correlation is represented by a straight line called the normal consolidation line, NCL, in e and lnp' space as shown in Figure 5 below. There is a set of straight lines intersecting the NCL known as swelling lines. These lines represent the unloadingreloading behaviour of the soil. The slope of the normally consolidated line is known as the isotropic logarithmic compression index, $\lambda$, while the slope of the swelling line is called the swelling index, $\kappa$. On the other hand, shearing a soil mass eventually leads to a state in which additional shearing results in no volumetric strain (?). This is called the critical state and is represented by the critical state line, CSL. This line is parallel to the normally consolidated line and hence has the same slope, $\lambda$, as shown in Figure 6 below.

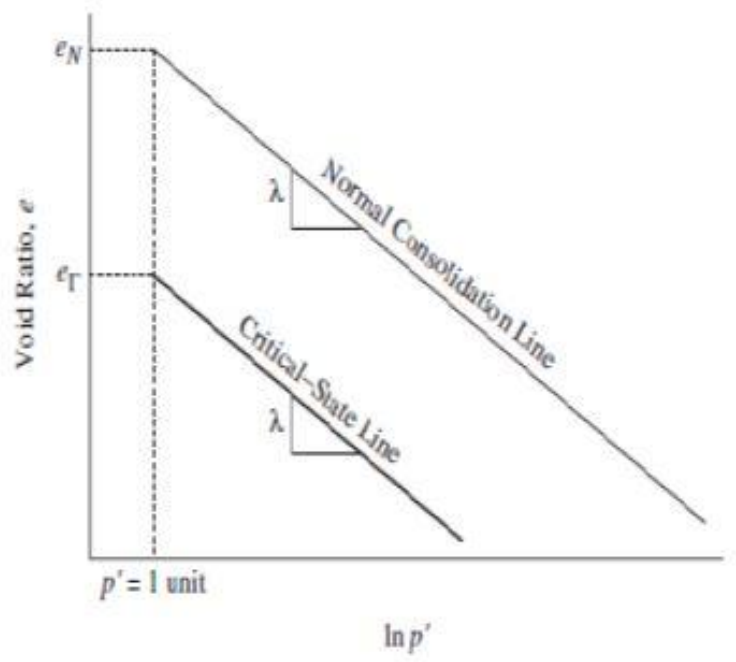

Fig. (5): Normal consolidated and critical state lines in e-lnp' space (Helwany, 2007)

\section{BOUNDRY CONDITIONS}

Fully constrained boundary condition was applied to the base of the soil mass. The right, left and the back faces of the clay layer were all constrained in the directions orthogonal to their planes. The front face of the soil mass is the plane of symmetry in which, movements in $\mathrm{x}$ and $\mathrm{z}$ directions were allowed, but not in the $\mathrm{z}$ direction. All the above-described boundaries were applied in the initial step of the analysis.

\section{ELEMENT TYPE AND MESH FORMATION}

Since the problem was modelled in a threedimensional domain, a 3D stress, quadratic tetrahedral element, C3D10, was employed to simulate the pile and the surrounding soil. The density of the elements was purposely made denser around the pile where the concentration of stresses and strains are expected. Mesh convergence studies were performed, and it was shown that this mesh refinement was sufficient enough to analyse the model with reasonable accuracy and minimum convergence issues. The total numbers of nodes and elements are 17677 and 10376 respectively.

\section{SOIL-PILE INTERFACE MODELING}

Pile- soil interaction was simulated by using the classic Coulomb model. The contact pair method built in ABAQUS was used to model the interaction at the interface between the soil and the pile. As the maximum shear stress is reached, total slip occurs, splitting any two surfaces in contact. Penalty friction formulation was used to identify the interaction properties of the soilreinforcement interface. 


\section{NUMERICAL SIMULATION}

The numerical analysis was carried out in two stages. In the first stage the boundary conditions, described in section (4), and the soil-pile interaction, described in section (6), were applied through an initial step. In the second stage, a moment was applied at the head of the pile.

\section{VALIDATION OF THE NUMERICAL ANALYSES}

The numerical models were verified, employing Brome's theory. The results of case studies are presented in the next section.

\section{RESULTS OF THE NUMERICAL ANALYSES}

Fig. 7 shows and compares the horizontal load and horizontal displacement obtained from the numerical and the analytical solutions. Regarding the numerical results, it should be noticed that the pile lateral load capacity $(=$ pile load $\times 2)$ because of symmetry. It is clear from the figure that the lateral displacement rises as the lateral load is increased up to a certain lateral displacement, at which a pile lateral displacement is encountered. Soon after that, the pile moves laterally at a greater rate, indicating that the lateral load capacity of the pile has been reached. While Brome's solution agrees well with the numerical analysis when the soil mass is homogeneous (i.e. one layer), it has under estimated the pile lateral load capacity when it is compared with the numerical solutions of case two and three respectively. This gross underestimation can be attributed to the limitations of the Brome's solutions, which assume that the pile-soil interaction is linear, and the embedded depth consists of a homogenous layer of soil. Further, the solution did not capture the influence of the variations of the undrain shear strength of the soil on the lateral capacity of the pile. As it can be seen from Fig. 7, a higher lateral resistance and lower head deflection can be obtained when the undrain shear strength of the upper layer is higher than the lower one. This is expected as the strength of the soil close to the pile head is proportional to the undrained strength.

\section{0- LATERAL EARTH PRESSURE DISSTRIBUTION ALONG THE PILE SHAFT}

The distribution of the lateral earth pressure with depth for case one obtained from the numerical analysis is presented in figure 8 , and compared with the distributions suggested by Broms' (1964) and Poulos and Davis (1980). Although the ultimate lateral resistance obtained from the finite element analysis for this case agrees with those predicted by Broms' theory, the distribution of lateral pressures predicted by either Broms or Poulos and Davis theories do not match with obtained results in this study.

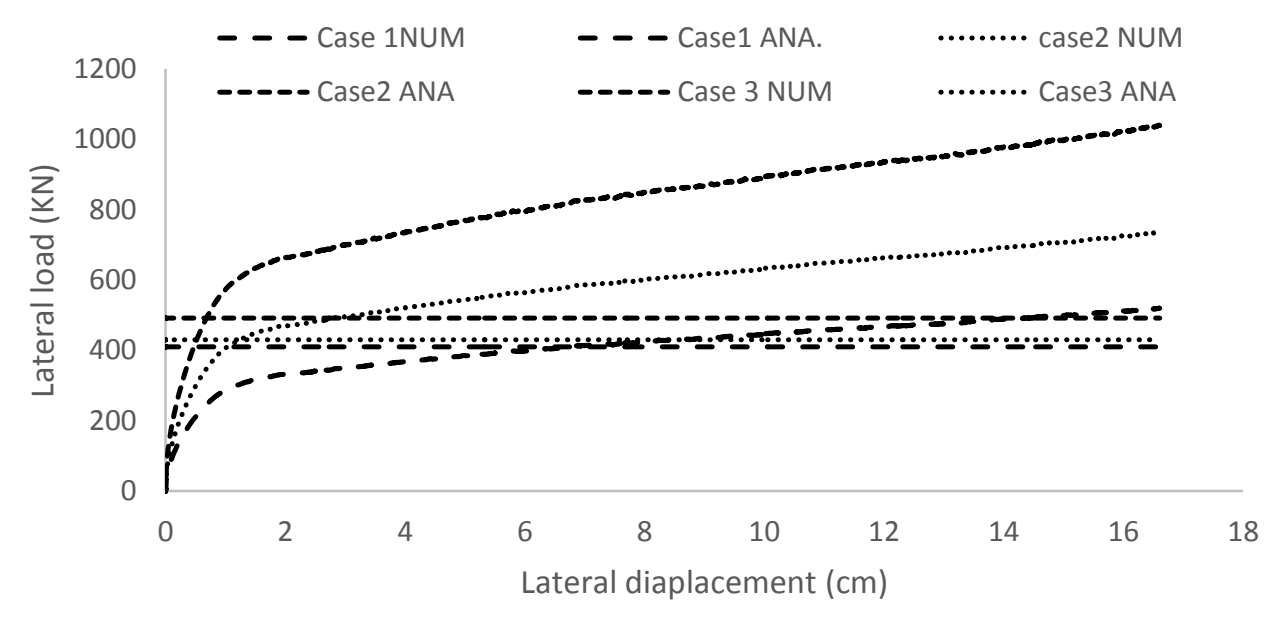

Fig. (7): Lateral load versus lateral displacement: Numerical versus analytical solutions. 


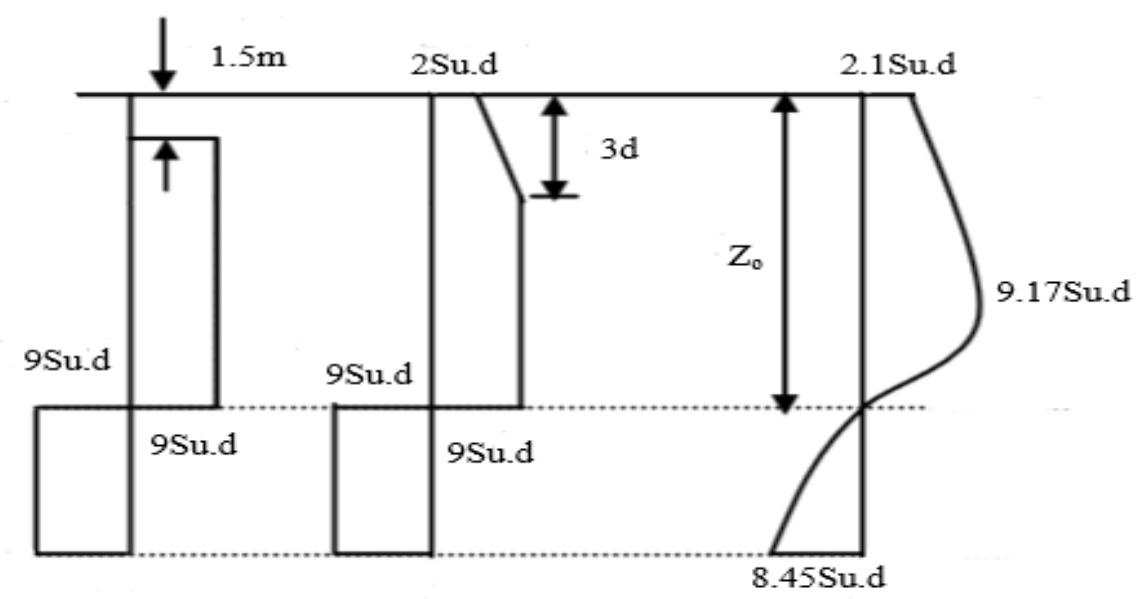

Fig. (8): Distribution of lateral earth pressure with depth. Left: Broms' (1964), Middle: Poulos and Davis (1981) and Right: current study.

\section{CONCLUSION}

A three-dimensional nonlinear numerical analyses were conducted to investigate the response of a single concrete rigid pile, driven in a hypothetical clayey soil and subjected to a lateral load under undrained conditions. The FE code, ABAQUS 6.12, was chosen for this purpose. The results of the study have shown that although Brom's solutions are very usable to quickly design a pile, the model is not very reliable if it is used in predicting the ultimate lateral resistance of a pile in a stratified continuum. The model has underestimated the ultimate lateral resistance of a single floating pile embedded in a layered cohesive soil when it was compared with the results of the numerical analyses.

Moreover, Broms' solution does not take into account the influence of the variations of the undrain shear strength on the lateral capacity of the pile. The numerical analyses have shown that a higher lateral resistance and lower head deflection can be obtained when the undrain shear strength of the upper layer is higher than the lower one.
Therefore, care must be practised when using Brom's solutions.

\section{REFERENCING}

- Barber E.S. (1953). Discussion to paper by S. M. Glesser. ASTM., 54: 96-99

- Bhushan K., Haley S.C. and Fong P.T. (1979). Lateral load tests on drilled piers in stiff clays. Journal of the Geotechnical Engineering, ASCE, 105(8): 969-985.

- Broms, B. (1965). Design of laterally loaded piles. Journal of the soil mechanics and foundation division , 91 (3), 77-99.

- Broms, B. (1964). Lateral resistance of piles in cohesionless soils. Journal of the soil mechanics and foundation division , 90 (3), 123-156.

- Broms, B. (1964). Lateral resistance of piles in cohesive soils. Journal of the soil mechanic and foundation division , 90 (2), 27-63.

- Druery B.M. and Ferguson B.A. (1969). An Experimental Investigation of the Behaviour of Laterally Loaded Piles. B. E. Thesis, Department of Civil Engineering, University of Sydney, Australia. 
- Hazzar, L., Karray, M., Bouassida, M., \& Hussien, M. N. (2013). Ultimate Lateral Resistance of

- Piles in Cohesive Soil. DFI Journal-The Journal of the Deep Foundations Institute, 7(1), 59-68.

- Helwany, S. (2007). Applied Soil Mechanics with ABAQUS Applications. New Jersey: JOHN WILEY \& SONS.

- McDonald P. (1999). Laterally loaded pile capacity revisited. Proc. of 8th Australia and New Zealand Conference on Geomechanics, Hobart, 1: 421-427.

- Meyerhof G.G., Mathur S.K. and Valsangkar A.J. (1981). Lateral resistance and deflection of rigid wall and piles in layered soils. Can. Geotech. J., 18: 159-170.
- Meyerhof G.G. and Sastry V.V.R.N. (1985). Bearing capacity of rigid piles under eccentric and inclined loads. Can. Geotech. J., 22: 267-276.

- Meyerhof G.G. and Yalcin A.S. (1984). Pile capacity for eccentric and inclined load in clay. Canadian Geotechnical Journal, 21: 389-396. Poulos H.G. (1971). Behavior of laterally loaded piles. I: Single piles. J. Soil Mech. and Found. Div., ASCE, 97(5): 711-731.

- Mukherjee, S., \& Dey, A. (2016) Analysis Of Laterally Loaded Fixed Headed Single Floating Pile In Multilayered Soil Using Bef Approach.

- Phanikanth, V. S., \& Choudhury, D. (2012). Effects of Lateral Loads on a Single Pile. Journal of The Institution of Engineers (India): Series A, 93(3), 163-173. 